\title{
Metabolic and hormonal response to intermittent high-intensity and continuous moderate intensity exercise in individuals with type 1 diabetes: a randomised crossover study
}

\author{
Lia Bally ${ }^{1}$ - Thomas Zueger ${ }^{1}$ - Tania Buehler ${ }^{2}$ Ayse S. Dokumaci ${ }^{2}$ Christian Speck ${ }^{1}$. \\ Nicola Pasi ${ }^{1}$ - Carlos Ciller $^{3,4}$ - Daniela Paganini ${ }^{1}$ - Katrin Feller ${ }^{1} \cdot$ Hannah Loher $^{1}$. \\ Robin Rosset ${ }^{5} \cdot$ Matthias Wilhelm $^{6} \cdot$ Luc Tappy $^{5} \cdot$ Chris Boesch $^{2} \cdot$ Christoph Stettler $^{1}$
}

Received: 3 September 2015 / Accepted: 9 December 2015 / Published online: 6 January 2016

(C) Springer-Verlag Berlin Heidelberg 2016

\begin{abstract}
Aims/hypothesis To investigate exercise-related fuel metabolism in intermittent high-intensity (IHE) and continuous moderate intensity (CONT) exercise in individuals with type 1 diabetes mellitus.

Methods In a prospective randomised open-label cross-over trial twelve male individuals with well-controlled type 1 diabetes underwent a $90 \mathrm{~min}$ iso-energetic cycling session at $50 \%$ maximal oxygen consumption $\left(\dot{V} \mathrm{O}_{2 \max }\right)$, with (IHE) or without (CONT) interspersed $10 \mathrm{~s}$ sprints every $10 \mathrm{~min}$ without insulin adaptation. Euglycaemia was maintained using oral ${ }^{13} \mathrm{C}$-labelled glucose. ${ }^{13} \mathrm{C}$ Magnetic resonance spectroscopy (MRS) served to quantify hepatocellular and intramyocellular glycogen. Measurements of glucose kinetics (stable isotopes), hormones and metabolites complemented the investigation. Results Glucose and insulin levels were comparable between interventions. Exogenous glucose requirements during the last
\end{abstract}

Christoph Stettler

christoph.stettler@insel.ch

1 Division of Endocrinology, Diabetes and Clinical Nutrition, Inselspital, Bern University Hospital, and University of Bern, CH-3010 Bern, Switzerland

2 Department Clinical Research and Department of Radiology, University of Bern, Bern, Switzerland

3 Department of Radiology, University Hospital Centre and University of Lausanne, Lausanne, Switzerland

4 Signal Processing Core, Centre for Biomedical Imaging (CIBM), Lausanne, Switzerland

5 Department of Physiology, Faculty of Biology and Medicine, University of Lausanne, Lausanne, Switzerland

6 Preventive Cardiology and Sports Medicine, Inselspital, Bern University Hospital, and University of Bern, Bern, Switzerland
$30 \mathrm{~min}$ of exercise were significantly lower in $\operatorname{IHE}(p=0.02)$. Hepatic glucose output did not differ significantly between interventions, but glucose disposal was significantly lower in IHE $(p<0.05)$. There was no significant difference in glycogen consumption. Growth hormone, catecholamine and lactate levels were significantly higher in IHE $(p<0.05)$.

Conclusions/interpretation IHE in individuals with type 1 diabetes without insulin adaptation reduced exogenous glucose requirements compared with CONT. The difference was not related to increased hepatic glucose output, nor to enhanced muscle glycogen utilisation, but to decreased glucose uptake. The lower glucose disposal in IHE implies a shift towards consumption of alternative substrates. These findings indicate a high flexibility of exercise-related fuel metabolism in type 1 diabetes, and point towards a novel and potentially beneficial role of IHE in these individuals.

Trial registration: ClinicalTrials.gov NCT02068638

Funding: Swiss National Science Foundation (grant number 320030 149321/) and R\&A Scherbarth Foundation (Switzerland).

Keywords Carbohydrate metabolism - Exercise . Hypoglycaemia $\cdot$ Metabolic physiology in vivo

$\begin{array}{ll}\text { Abbreviations } \\ \text { AU } & \text { Arbitrary units } \\ \text { BMR } & \text { Basic metabolic rate } \\ \text { CGM } & \text { Continuous glucose monitoring } \\ \text { CHO } & \text { Carbohydrate } \\ \text { CONT } & \text { Continuous moderate intensity exercise } \\ \text { GH } & \text { Growth hormone } \\ \text { IE } & \text { Isotopic enrichment } \\ \text { IHE } & \text { Intermittent high-intensity exercise }\end{array}$


IMCL Intramyocellular lipids

MRS Magnetic resonance spectroscopy

$\mathrm{Ra} \quad$ Rate of glucose appearance

$\mathrm{Ra}_{\text {exo }} \quad$ Rate of exogenous glucose appearance

$\mathrm{Ra}_{\text {hep }} \quad$ Rate of hepatic glucose appearance

Rd Rate of glucose disappearance

RER Respiratory exchange ratio

$\dot{V} \mathrm{O}_{2} \quad$ Oxygen consumption

$\dot{V} \mathrm{O}_{2 \max }$ Maximal oxygen consumption

\section{Introduction}

Despite its well-defined health benefits, exercise imposes high demands on individuals with type 1 diabetes [1]. Adaptation of exercise-related insulin may prevent hypoglycaemia but in clinical practice not all patients with type 1 diabetes follow treatment recommendations to adapt exercise-related insulin due to different reasons.

Intermittent high-intensity exercise (IHE) has become a widespread training modality given its well-established benefits on exercise performance and cardiovascular and metabolic variables $[2,3]$. IHE consists of repeated bouts of supramaximal efforts interrupting longer periods of low to moderate intensity activity. So far, a limited number of studies have investigated IHE in type 1 diabetes, generally reporting a glycaemiastabilising effect when compared with continuous moderate intensity exercise (CONT) [4-11]. However, exercise in the majority of these studies was of limited duration and data regarding longer IHE duration are scarce [7]. In clinical practice the problem of exercise-associated hypoglycaemia is frequently encountered during activities of longer duration, and it is currently unclear whether IHE might even be beneficial for type 1 diabetes in this context. Moreover, since the majority of previous studies investigating IHE essentially focused on blood glucose dynamics, the underlying physiological mechanisms are still ill defined. It is thought that a major glucose-stabilising effect of IHE lies in the increased hepatic glucose output stimulated by counterregulatory hormones [12]. More recent data suggest that additional mechanisms may be involved, particularly pointing towards a change in peripheral glucose disposal induced by high-intensity exercise [13].

The aim of the present study was to investigate the metabolic and hormonal response to IHE and CONT in individuals with type 1 diabetes under conditions reflecting daily clinical practice (i.e. euglycaemia maintained by oral glucose, no specific pre-exercise insulin adaptation). The study combined stable isotope techniques, non-invasive measurement of glycogen in liver and skeletal muscle by magnetic resonance spectroscopy (MRS), and assessment of whole body substrate utilisation, and continuous glucose monitoring (CGM) to follow post-exercise glycaemia. Our main hypothesis was that the amount of exogenous glucose required to maintain euglycaemia would be lower during IHE compared with CONT. The secondary hypothesis was that such a difference would be explained by a higher consumption of glycogen during IHE.

\section{Methods}

Inclusion criteria Twelve recreationally active young male adults with well-controlled, complication-free type 1 diabetes (three, multiple daily injections; nine, continuous s.c. insulin infusion) were recruited for this study. Volunteers were eligible if they had undetectable C-peptide, stable insulin regimen for at least 3 months prior to the study and were not taking any prescribed medication other than insulin. Written informed consent was obtained and the Local Ethics Committee approved the study.

Experimental design and protocol This was a prospective, randomised, crossover trial. Randomisation was performed by sealed opaque envelopes. Preliminary study visits included an indirect calorimetry to determine basic metabolic rate (BMR), a bioimpedance analysis for lean body mass calculation (BIA 101, Akern, Pontassieve FI, Italy) and a stepwise incremental exercise test on a bicycle ergometer with breath-to-breath spiroergometry (Cardiovit AT-104 PC; Schiller, Baar, Switzerland) as described previously [14].

The exercise intervention consisted of a $90 \mathrm{~min}$ isoenergetic (based on energy expenditure assessed by oxygen consumption $\left[\dot{V} \mathrm{O}_{2}\right]$ measurements) cycling session at $50 \%$ maximal oxygen consumption $\left(\dot{V} \mathrm{O}_{2 \max }\right)$ with IHE or without CONT interspersed $10 \mathrm{~s}$ supramaximal sprints every $10 \mathrm{~min}$ (at $120 \%$ of individual peak work load, followed by a $50 \mathrm{~s}$ recovery phase to equalise energy expenditure of the two exercise protocols, first sprint after $10 \mathrm{~min}$ ). Interventions were separated by $2-4$ weeks. Prior to the first intervention, patients were familiarised with study procedures including a full ride over 90 min with the first half involving repeated $10 \mathrm{~s}$ sprints. Over the entire study period glycaemia was targeted at $8 \mathrm{mmol} / \mathrm{l}$ by oral administration of a $10 \%$ dextrose solution according to a pre-specified carbohydrate $(\mathrm{CHO})$ intake algorithm with individual adaptations [15]. The primary outcome was the $\mathrm{CHO}$ intake within the last $30 \mathrm{~min}$ of the exercise session.

Pre-study standardisation procedures and post-exercise follow up During the $48 \mathrm{~h}$ before exercise interventions participants consumed a standardised diet with a pre-defined daily $\mathrm{CHO}$ quantity corresponding to $50 \%$ of their calculated energy expenditure [16] and diet was replicated prior to the second exercise intervention. Foods naturally enriched in ${ }^{13} \mathrm{C}$-labelled $\mathrm{CHO}$ were avoided to limit baseline shifts in 
expired ${ }^{13} \mathrm{CO}_{2}$ [17]. In addition, they were requested to avoid strenuous exercise (pedometer record $<5,000$ steps/day), alcohol and caffeine. Patients adhered to their usual insulin regimen and glycaemia was assessed using CGM (Dexcom G4 Platinum) and frequent capillary glucose measurements. On study day participants had a standardised breakfast (1/6 of individual daily $\mathrm{CHO}$ amount) covered by their usual insulin dose before 07:00 hours and were admitted to the research facility at 09:30 hours. No adjustment in insulin therapy was made in anticipation of exercise and insulin dosage was the same for both trials.

After exercise patients were offered a standardised meal, fitted with a new CGM system and discharged at 17:00-18:00 hours. This was followed by an outpatient investigation of CGM, CHO intake and activity level until 06:00 hours the following day.

\section{Sampling procedures for metabolites and hormones On} arrival an $18 \mathrm{G}$ cannula was inserted into an antecubital vein of each forearm. Glycaemia was measured every $10 \mathrm{~min}$ (YSI2300; Yellow Springs Instruments, Yellow Springs, OH, USA). Sampling for insulin, counter-regulatory hormones (catecholamines, growth hormone [GH], glucagon, cortisol) and metabolites (lactate, NEFA) was performed $50 \mathrm{~min}$ prior to exercise, at 10, 30, 60 and $80 \mathrm{~min}$ of exercise, as well as in the recovery phase $120 \mathrm{~min}$ after exercise. Insulin, GH and cortisol were measured using immunoassays (insulin: Architect, Abbott, Baar, Switzerland; GH:Immulite, Siemens, Zürich, Switzerland; cortisol: Modular, Roche, Rotkreuz, Switzerland). Glucagon was measured using a double radioimmunoassay (Siemens, Zürich, Switzerland) in EDTA plasma mixed with aprotinin, immediately cooled and frozen after separation. NEFA were assessed using a kit from Wako Chemicals (Dietikon, Switzerland). Lactate, $\mathrm{pH}$, bicarbonate, oxygen and $\mathrm{CO}_{2}$ tension were determined electrochemically using the ABL 835/837 FLEX (Radiometer, Thalwil, Switzerland) analyser. Plasma catecholamines were quantified using ultraperformance liquid chromatographytandem mass spectrometry (Waters Acquity UPLC/TQD, Manchester, UK) [18].

\section{Cardiopulmonary monitoring, respiratory gas exchange} and substrate oxidation Resting $\mathrm{CO}_{2}$ consumption $\left(\dot{V} \mathrm{CO}_{2}\right)$ and $\dot{V} \mathrm{O}_{2}$ were measured immediately before exercise and in the recovery phase $120 \mathrm{~min}$ after exercise. The $90 \mathrm{~min}$ exercise session involved six spirometric recording phases, each performed over $5 \mathrm{~min}$ prior to the next sprint to avoid excess $\mathrm{CO}_{2}$ arising from the bicarbonate buffering system. Net substrate oxidation and energy expenditure were calculated from standard indirect calorimetry equations [19]. Heart rate was recorded continuously by a portable three channel ECG (Lifecard CF, Del Mar Reynolds Medical, Irvine, CA, USA).
Stable isotopes Orally supplied glucose (100 g glucose/1; Glucosum monohydricum, Hänseler AG, Herisau, Switzerland) labelled with $0.5 \%\left[\mathrm{U}_{-}{ }^{13} \mathrm{C}_{6}\right]$ glucose was used in combination with infused $\left[6,6{ }^{2} \mathrm{H}_{2}\right]$ glucose (Cambridge Isotope Laboratories, Tewksbury, MA, USA). Double background enrichment measurements (blood and breath samples) were taken immediately after i.v. cannulation at test onset. Twenty minutes before exercise, a primed $\left(0.6 \mathrm{mg} \mathrm{kg}^{-1}[\mathrm{mmol} / 1 \text { glucose }]^{-1}\right)$ constant infusion of $30 \mu \mathrm{g}\left(\left[6,6^{2}{ }^{2} \mathrm{H}_{2}\right]\right.$ glucose $) \mathrm{kg}^{-1} \mathrm{~min}^{-1}$ was initiated. With exercise onset the $\left[6,6-{ }^{2} \mathrm{H}_{2}\right]$ glucose infusion rate was quadrupled to minimise changes in enrichment [20]. Measurements were obtained during the last $30 \mathrm{~min}$ of exercise (at 59, 69, 79 and $89 \mathrm{~min}$ ), thereby allowing for a $60 \mathrm{~min}$ equilibration period, which was deemed adequate given the high glucose turnover rate during exercise. Plasma $\left[6,6-{ }^{2} \mathrm{H}_{2}\right]$ glucose and $\left[{ }^{13} \mathrm{C}\right]$ glucose isotopic enrichment (IE) were measured using GC-MS (Hewlett-Packard Instruments, Palo Alto, CA, USA) in chemical ionisation mode as previously described $[21] .{ }^{13} \mathrm{CO}_{2} \mathrm{IE}$ was measured by isotope-ratio MS (SerCon, Crewe, UK).

Calculations of glucose kinetics The total rate of glucose appearance $(\mathrm{Ra})$ reflects the sum of hepatic glucose production $\left(R a_{\text {hep }}\right)$ and the rate of exogenous glucose appearing in the circulation $\left(\mathrm{Ra}_{\mathrm{exo}}\right)$. $\mathrm{Ra}$ and rate of disappearance (Rd) during the last $30 \mathrm{~min}$ of exercise were calculated from $\left[6,6-{ }^{2} \mathrm{H}_{2}\right]$ glucose dilution using Steele's equation for non-steady state conditions assuming an effective fraction of 0.65 and a distribution volume of $0.22 \mathrm{l} / \mathrm{kg}$ [22]. $\mathrm{Ra}_{\text {exo }}$ was computed as plasma $\left[{ }^{13} \mathrm{C}\right]$ glucose IE/oral $\left[{ }^{13} \mathrm{C}\right]$ glucose IE $\times$ Ra. The oxidation rate of plasma glucose was calculated from ${ }^{13} \mathrm{C} \mathrm{IE}$ in plasma and breath, using a ${ }^{13} \mathrm{CO}_{2}$ recovery factor of 1.0 [23]. The ratio of ${ }^{13} \mathrm{C}$-abundance in the expired air and ingested glucose drink provided an estimate of the amount of oxidised exogenous glucose. The oxidation rate of glucose released by the liver was estimated by the difference between the oxidation rate of plasma and exogenous glucose. The difference between net $\mathrm{CHO}$ oxidation and the oxidation of plasma glucose was used to compute oxidation of muscle glycogen. A bicarbonate correction factor assuming a bicarbonate pool of $14.2 \mathrm{mmol} / \mathrm{kg}$ was applied for estimating $\left[{ }^{13} \mathrm{C}\right]$ glucose oxidation [24].

MRS Glycogen content in quadriceps muscle and liver was assessed using natural abundance ${ }^{13} \mathrm{C}$ MRS $[25,26]$. Measurements were performed on a 3 Tesla MR system (Trio, Siemens, Erlangen, Germany) before and after exercise. To avoid interference (e.g. increased stress response induced by the need to permanently hold an inconvenient position in the MR) a baseline MRS was scheduled 1 week prior to the experiments after an identical standardisation period. A ${ }^{1} \mathrm{H} /{ }^{13} \mathrm{C}$-transmit-receive surface coil (RAPID Biomedical, Rimpar Germany) was tightly positioned over the tissues of interest. Positioning and repositioning of the coil were monitored by a series of localiser images and an additional fixation 
point on the body. ${ }^{13} \mathrm{C}$ spectra were acquired by a pulse-andacquire sequence using an adiabatic excitation pulse and ${ }^{1} \mathrm{H}$-decoupling (TR $200 \mathrm{~ms}$, acquisition time $14 \mathrm{~min}$ [muscle] and $21 \mathrm{~min}$ [liver]). A chromium-doped acetone solution served as an external reference to correct for coil loading effects. In liver spatial saturation bands were applied to suppress glycogen signals (placed at carrier frequency) from the abdominal wall muscles. Glycogen content was quantified by integration of the $\mathrm{C} 1$ glycogen resonance at 100.5 parts per million (ppm). Glycogen levels are indicated in arbitrary units (AU).

Sample size considerations and statistical analysis To detect a difference of $64 \mathrm{ml}(\mathrm{SD} 70 \mathrm{ml})$ of $20 \%$ glucose given during exercise with $5 \%$ significance and a power of $80 \%$, a sample of ten participants was deemed necessary [7]. To account for potential dropouts the final sample size was set at 12 participants. There were no dropouts, therefore all analyses were performed with 12 individuals.

Data were analysed using Stata 13.0 (Stata Corporation, College Station, TX, USA), Matlab R2015a (The MathWorks, Natick, MA, USA) and GraphPad Prism software 5.0 (GraphPad Software, San Diego, CA, USA). Differences in hormones, metabolites and substrate oxidation were identified by paired comparison of AUCs. Glucose kinetics were compared based on values during the last $30 \mathrm{~min}$ of exercise. Continuous variables were analysed for normal distribution using Shapiro-Wilk test and qq-plots. Student's paired $t$ tests were used to identify differences for normally distributed data, and Wilcoxon's signed rank tests were used for non-parametric data. A $p$ value of $<0.05$ was considered statistically significant. Values are expressed as mean \pm SEM, unless otherwise specified.

\section{Results}

Patient characteristics and pre-study standardisation Detailed physical and functional characteristics are shown in Table 1. During the pre-study phase daily $\mathrm{CHO}$ intake and insulin dosage were similar (CHO: $348 \pm 9$ vs $359 \pm 11 \mathrm{~g}, p=0.22$; insulin: $72 \pm 5$ vs $72 \pm 4 \mathrm{U}, p=0.97$ for IHE and CONT). The average basal insulin dose did not differ between trials (29.0 \pm 2.5 vs $28.6 \pm 2.5 \mathrm{U} / 24 \mathrm{~h}$ for IHE and CONT, $p=0.25$ ).

Glycaemia, insulin levels and CHO requirements During exercise, glucose $(7.88 \pm 0.22$ vs $7.29 \pm 0.20 \mathrm{mmol} / 1, p=0.16)$ and insulin $(150.7 \pm 11.5$ vs $148.5 \pm 15.1 \mathrm{pmol} / 1, p=0.50)$ levels did not differ between IHE and CONT. Insulin levels $120 \mathrm{~min}$ after end of exercise were $80.4 \pm 12.2 \mathrm{pmol} / \mathrm{l}$ in IHE and $102.6 \pm 20.8 \mathrm{pmol} / 1$ in CONT $(p=0.13)$. Corresponding glycaemia was $8.02 \pm 0.61$ and $10.09 \pm 1.13 \mathrm{mmol} / \mathrm{l}$ following IHE and CONT $(p=0.08)$ (Fig. 1a, d). Total energy expenditure over 90 min exercise was $3.35 \pm 0.15$ and $3.30 \pm 0.13 \mathrm{MJ}$
Table 1 Baseline characteristics of study patients

\begin{tabular}{ll}
\hline Characteristic & $n=12$ \\
\hline Age (years) & $26.2 \pm 3.9$ \\
Weight (kg) & $82.0 \pm 10.8$ \\
Height (m) & $1.80 \pm 0.04$ \\
BMI (kg/m $\left.{ }^{2}\right)$ & $25.2 \pm 3.4$ \\
Fat-free mass (\%) & $77.24 \pm 6.9$ \\
$\mathrm{BMR}(\mathrm{MJ} /$ day) & $8.60 \pm 0.83$ \\
$\dot{V} \mathrm{O}_{2 \mathrm{max}}\left(\mathrm{ml}\left[\mathrm{kg}\right.\right.$ body weight] $\left.{ }^{-1} \mathrm{~min}^{-1}\right)$ & $47.9 \pm 10.2$ \\
Diabetes duration (years) & $14.2 \pm 6.2$ \\
$\mathrm{HbA}_{1 \mathrm{c}}(\%)$ & $7.0 \pm 0.6$ \\
$\mathrm{HbA}_{1 \mathrm{c}}(\mathrm{mmol} / \mathrm{mol})$ & $54 \pm 6$ \\
Total average daily insulin $\left(\mathrm{U} \mathrm{kg}^{-1}\right.$ day $\left.^{-1}\right)$ & $0.72 \pm 0.10$ \\
\hline
\end{tabular}

Data are expressed as mean $\pm \mathrm{SD}$

for IHE and CONT $(p=0.67)$. Average heart rate was similar in IHE and CONT (142 \pm 2 vs $136 \pm 4$ beats/min, $p=0.28)$. $\mathrm{CHO}$ requirements during the last $30 \mathrm{~min}$ of exercise were significantly lower in IHE ( $6 \pm 2 \mathrm{~g})$ when compared with CONT (15 $\pm 4 \mathrm{~g}, p=0.02)$. CHO amounts supplied during the $120 \mathrm{~min}$ post-exercise were comparable (IHE $10 \pm 3$, CONT $14 \pm 3 \mathrm{~g}, p=0.22$ ).

Counter-regulatory hormones and metabolites There were no significant baseline differences for all assessed variables (Fig. 1a-i). Mean glucagon levels during exercise were $14.9 \pm 0.9$ and $13.3 \pm 0.6 \mathrm{pmol} / 1$ in IHE and CONT $(p=0.21)$. GH was significantly higher during IHE when compared with CONT $(15.6 \pm 2.0$ vs $10.3 \pm 1.3 \mathrm{ng} / \mathrm{ml}, p=0.02)$. Exerciseinduced increase in cortisol was comparable between interventions with mean levels of $510.8 \pm 35.8$ and $461.5 \pm 27.3 \mathrm{nmol} / \mathrm{l}$ in IHE and CONT $(p=0.28)$. During exercise catecholamines were significantly higher in IHE compared with CONT $(p<0.001$ for noradrenaline [norepinephrine] and 0.002 for adrenaline [epinephrine]). Hormones did not differ in the post-exercise period. During IHE lactate was significantly higher when compared with CONT ( $7.3 \pm 0.4$ vs $2.0 \pm 1.2 \mathrm{mmol} / \mathrm{l}, p<0.001)$ but not at $120 \mathrm{~min}$ after exercise completion. During exercise significantly lower $\mathrm{pH}$ was observed in IHE when compared with CONT (pH: $7.27 \pm 0.01$ vs $7.38 \pm 0.00, p<0.001)$. NEFAs during exercise were $0.3 \pm 0.03 \mathrm{mmol} / \mathrm{l}$ in IHE and $0.5 \pm 0.04 \mathrm{mmol} / \mathrm{l}$ in CONT $(p=0.06)$.

Substrate oxidation and glucose kinetics There were no significant differences in pre-exercise or post-exercise respiratory exchange ratio (RER) values between IHE and CONT (Table 2). During exercise, CHO oxidation rate was $24.74 \pm 0.77 \mathrm{mg} \mathrm{kg}^{-1} \mathrm{~min}^{-1}$ in IHE and $25.73 \pm 0.74 \mathrm{mg} \mathrm{kg}^{-1} \mathrm{~min}^{-1}$ in CONT $(p=0.60)$. Fat oxidation tended to be higher in IHE compared with 

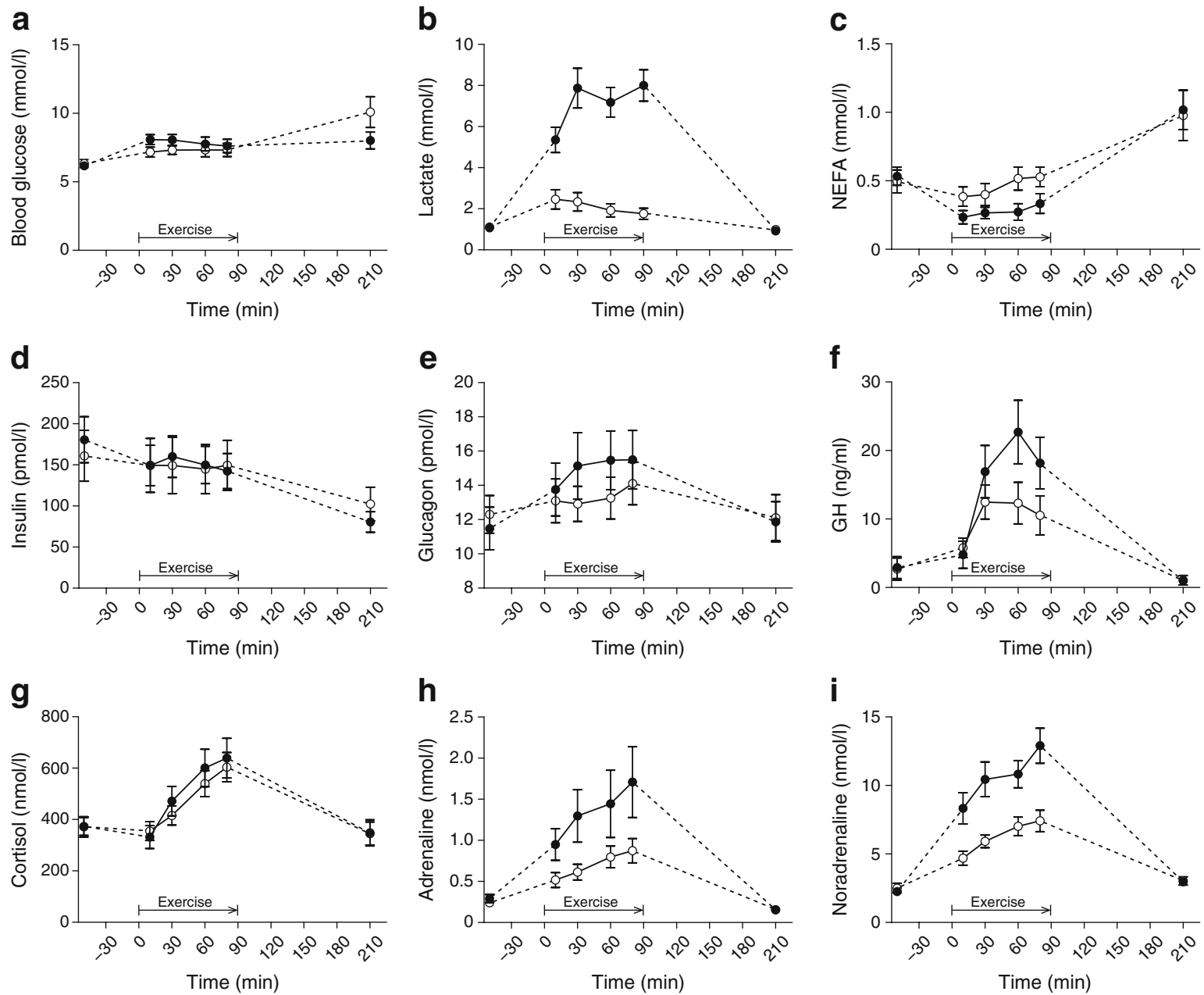

Fig. 1 Effect of $90 \mathrm{~min}$ of IHE (black circles) and CONT (white circles) on blood glucose (a) $(p=0.16)$, lactate (b) $(p<0.001)$, NEFA (c) $(p=0.06)$, insulin (d) $(p=0.50)$, glucagon (e) $(p=0.21)$, GH (f) $(p=0.02)$, cortisol (g) $(p=0.28)$, adrenaline (h), $(p=0.002)$ and noradrenaline (i) $(p<0.001)$ levels

Table 2 Respiratory gas exchange and net substrate oxidation rates

\begin{tabular}{lllll}
\hline Variable & Pre-exercise & Exercise 0-60 min & Exercise 60-90 min & Post-exercise \\
\hline RER & & & & \\
IHE & $0.83 \pm 0.01$ & $0.93 \pm 0.01$ & $0.92 \pm 0.01$ & $0.77 \pm 0.02$ \\
CONT & $0.85 \pm 0.01$ & $0.95 \pm 0.01$ & $0.93 \pm 0.01$ & $0.78 \pm 0.02$ \\
$\quad p$ value & 0.17 & 0.13 & 0.14 & 0.51 \\
CHOox (mg kg & min $^{-1}$ ) & & & \\
IHE & $2.42 \pm 0.26$ & $24.90 \pm 1.03$ & $24.21 \pm 0.97$ & $1.15 \pm 0.37$ \\
CONT & $3.01 \pm 0.30$ & $25.92 \pm 0.99$ & $25.58 \pm 0.93$ & $1.34 \pm 0.42$ \\
$\quad p$ value & 0.09 & 0.58 & 0.26 & 0.34 \\
FATox (mg kg & $\mathrm{min}^{-1}$ ) & & & $1.49 \pm 0.20$ \\
IHE & $1.36 \pm 0.16$ & $2.72 \pm 0.28$ & $3.03 \pm 0.26$ & $1.63 \pm 0.22$ \\
CONT & $1.31 \pm 0.17$ & $2.04 \pm 0.25$ & $2.49 \pm 0.24$ & 0.29 \\
$\quad p$ value & 0.80 & 0.09 & 0.26 & \\
\hline
\end{tabular}

Data presented as mean \pm SEM

Values represent average of 5 min recording phases

CHOox, carbohydrate oxidation, FATox, fat oxidation 


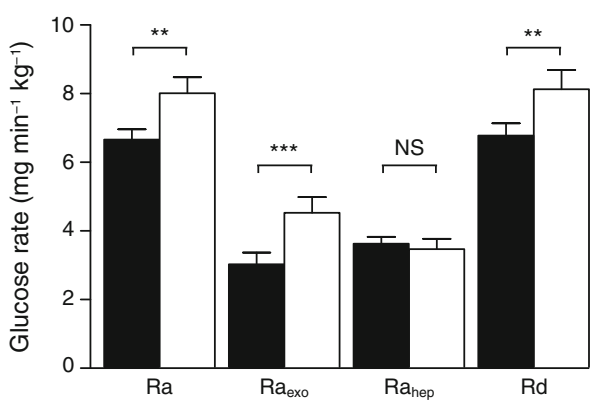

Fig. 2 Glucose fluxes during the last $30 \mathrm{~min}$ of IHE (black bars) and CONT (white bars). ${ }^{* *} p<0.01,{ }^{* * *} p<0.001$, NS, not significant $(p=0.69)$

CONT $\left(2.82 \pm 0.20\right.$ vs $2.30 \pm 0.19 \mathrm{mg} \mathrm{kg}^{-1} \mathrm{~min}^{-1}$, $p=0.13$ ).

Figure 2 summarises glucose kinetics during the last $30 \mathrm{~min}$ of exercise. Ra was significantly lower in IHE compared with CONT $\left(6.68 \pm 0.30\right.$ vs $\left.8.02 \pm 0.46 \mathrm{mg} \mathrm{kg}^{-1} \mathrm{~min}^{-1}, p<0.01\right)$. This was essentially due to a significantly lower rate of $\mathrm{Ra}_{\text {exo }}$ in the systemic circulation in IHE when compared with CONT $\left(\mathrm{Ra}_{\text {exo }}\right.$ : $3.06 \pm 0.33$ vs $\left.4.53 \pm 0.45 \mathrm{mg} \mathrm{kg}^{-1} \mathrm{~min}^{-1}, p<0.001\right)$. In contrast, $\mathrm{Ra}_{\text {hep }}$ did not differ significantly between interventions $\left(3.63 \pm 0.20\right.$ vs $3.49 \pm 0.29 \mathrm{mg} \mathrm{kg}^{-1} \mathrm{~min}^{-1}$ for IHE and CONT, respectively; $p=0.69$ ). Rd was significantly lower in IHE when compared with CONT $(6.80 \pm 0.36$ vs $\left.8.15 \pm 0.55 \mathrm{mg} \mathrm{kg}^{-1} \mathrm{~min}^{-1}, p<0.01\right)$. Accordingly, metabolic clearance rate was significantly lower in IHE when compared with CONT (5.31 \pm 0.34 vs $\left.6.46 \pm 0.51 \mathrm{ml} \mathrm{kg}^{-1} \mathrm{~min}^{-1}, p=0.02\right)$.

${ }^{13} \mathrm{C}$ IE in expired air and plasma revealed a lower oxidation rate of exogenous glucose in IHE when compared with CONT $\left(2.62 \pm 0.28\right.$ vs $\left.3.59 \pm 0.32 \mathrm{mg} \mathrm{kg}^{-1} \min ^{-1}, p<0.01\right)$. The oxidation rate of plasma glucose was $5.81 \pm 0.33$ vs $6.33 \pm 0.38 \mathrm{mg} \mathrm{kg}^{-1} \mathrm{~min}^{-1}$ for IHE and CONT, respectively $(p=0.12)$. Similarly, the rate of oxidised hepatic glucose did not differ significantly between interventions $(3.20 \pm 0.30$ vs $2.74 \pm 0.31 \mathrm{mg} \mathrm{kg}^{-1} \mathrm{~min}^{-1}$ for IHE and CONT, respectively; $p=0.29)$. Calculated rate of muscle glycogen oxidation was similar $\left(17.86 \pm 0.77\right.$ vs $18.89 \pm 0.90 \mathrm{mg} \mathrm{kg}^{-1} \mathrm{~min}^{-1}$ for IHE and CONT, respectively; $p=0.41)$.
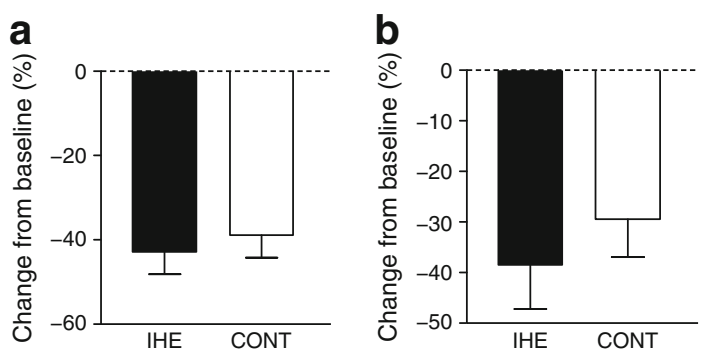

Fig. 3 Results from ${ }^{13} \mathrm{C}$ MRS for the change in intramyocellular (a) and hepatocellular (b) glycogen following 90 min of IHE (black bars) and CONT (white bars); $p$ for difference between IHE and CONT $=0.63$ in intramyocellular and 0.36 in hepatocellular glycogen levels

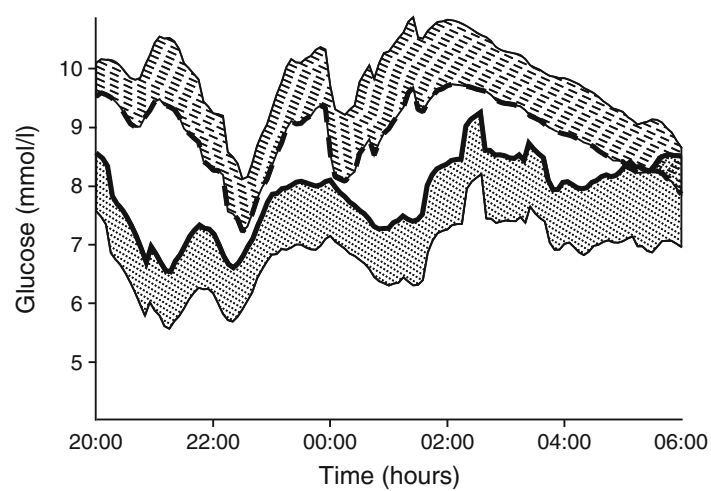

Fig. 4 Nocturnal CGM after IHE (bold solid line) and CONT (bold dashed line); dotted and dashed areas represent SEM

Glycogen assessment by MRS Exercise-related relative changes in intramyocellular and hepatocellular glycogen levels are depicted in Fig. 3. The 90 min exercise session resulted in a significant decrease in glycogen levels in skeletal muscle $(-59 \pm 8 \mathrm{AU}$ in $\mathrm{IHE},-56 \pm 7 \mathrm{AU}$ in CONT, $p<0.01)$ and liver $(-54 \pm 13 \mathrm{AU}$ in IHE, $-41 \pm 12 \mathrm{AU}$, $p<0.01)$. The relative change in intramyocellular glycogen levels was $-42.9 \pm 5.3 \%$ in IHE and $-40.5 \pm 4.6 \%$ in CONT $(p=0.63)$. Liver glycogen decreased by $38 \pm 8.8 \%$ in IHE and $29.2 \% \pm 7.5 \%$ in CONT $(p=0.36)$.

Post-exercise follow-up overnight Figure 4 shows results of post-exercise overnight CGM. Mean glucose was $7.85 \pm 0.72 \mathrm{mmol} / 1$ for IHE and $8.80 \pm 0.64 \mathrm{mmol} / 1$ for CONT $(p=0.04)$. The average number of hypoglycaemic $(<3.5 \mathrm{mmol} / \mathrm{l})$ events was $1.18 \pm 0.42$ (IHE) and $0.58 \pm 0.32$ (CONT, $p=0.39)$. Average time spent in hypoglycaemia (IHE $20 \pm 9$ vs CONT $10 \pm 6 \min , p=0.52$ ) and hyperglycaemia (IHE $107 \pm 40$ vs CONT $106 \pm 35 \mathrm{~min}$, $p=0.87$ ) was similar. In both interventions, $64 \%$ of observed hypoglycaemias were above $3 \mathrm{mmol} / \mathrm{l}$. There was no significant difference in glucose variability measures between IHE and CONT (SD: $2.45 \pm 0.33$ vs $2.38 \pm 0.21 \mathrm{mmol} / 1, p=0.95$; CV: $0.31 \pm 0.03$ vs $0.28 \pm 0.03, p=0.54$; mean amplitude of glycaemic excursions: $5.13 \pm 0.51$ vs $5.31 \pm 0.55, p=0.63$ ).

Post-exercise $\mathrm{CHO}$ intake tended to be higher in IHE $(233 \pm 15 \mathrm{~g})$ compared with CONT (212 $\pm 15 \mathrm{~g}, p=0.06)$. The concomitantly administered total insulin (bolus and basal insulin) was comparable between the conditions $(43 \pm 3$ vs $44 \pm 2 \mathrm{U}$ for IHE and CONT, respectively; $p=0.56)$.

\section{Discussion}

This study comprehensively assessed the hormonal and metabolic response to an IHE and CONT of $90 \mathrm{~min}$ in male adults with well-controlled type 1 diabetes under euglycaemia and without insulin adaptation. The principal findings were: (1) a 
lower amount of exogenous $\mathrm{CHO}$ was required to maintain euglycaemia during IHE compared with CONT; (2) this finding was not related to an increased hepatic glucose output but to a significantly lower glucose disposal in IHE compared with CONT; (3) metabolically, this was paralleled by increased levels of counter-regulatory hormones (mainly GH and catecholamines), as well as substantially higher levels of lactate in IHE; and (4) there was no measurable difference in the consumption of intramyocellular and hepatic glycogen between IHE and CONT.

The finding of $\sim 50 \%$ lower amounts of exogenous glucose required to uphold euglycaemia during the last $30 \mathrm{~min}$ of IHE confirmed our study hypothesis. However, the amount may appear disproportionate compared with the significantly smaller difference in the rates of exogenous glucose appearing in the systemic circulation $\left(\mathrm{Ra}_{\mathrm{exo}}\right)$. This discrepancy may be explained by the physiological delay between glucose ingestion and systemic appearance given that $\mathrm{Ra}_{\mathrm{exo}}$ in the present study was assessed during the last $30 \mathrm{~min}$ of exercise, exclusively.

The lower glucose disposal observed in IHE was somehow unexpected and in contrast to the secondary hypothesis. As suggested before by others, we had expected IHE, due to an increase in counter-regulatory hormones, to translate into an increased hepatic glucose output as a result of hepatic glycogenolyis and/or gluconeogenesis [12]. Indeed, we observed an increase in stress hormones, but resulting in a decreased glucose clearance instead of increased hepatic glucose output. Interestingly, it has recently been shown that a single $10 \mathrm{~s}$ supramaximal sprint may acutely reduce the $\mathrm{Rd}$ while leaving Ra unaffected in both healthy individuals and patients with type 1 diabetes [13]. This points towards a rapid change in peripheral insulin sensitivity associated with intensive exercise bouts. As shown in previous reports in individuals with type 1 diabetes $[6,8,9]$, IHE in the present study induced a strong and persistent increase in counter-regulatory hormones, mainly catecholamines and GH. Previous research consistently suggests that high levels of GH are associated with a comparably rapid reduction of peripheral glucose uptake [27]. In addition, there is evidence that increased levels of catecholamines may also antagonise insulin-mediated glucose uptake in skeletal muscle [28, 29].

Another potential explanation for the lower Rd in IHE may be related to competing substrates being used by the working muscle during IHE. The significantly higher lactate levels in IHE in the present study may be interpreted in this sense. The role of lactate as a glucose-competing agent is supported by recent clamp studies showing that increased lactate utilisation was associated with decreased glucose disappearance during moderate intensity exercise [30]. Similarly, animal studies observed reduced glucose uptake by the muscle in the presence of hyperlactataemia [31-33]. Due to the design of the present study we can only speculate on potential mechanisms related to elevated lactate levels during IHE. It may stem from working muscle producing more lactate during intensive exercise bouts in IHE than in CONT. However, the finding of similar consumption of intramyocellular glycogen in IHE and CONT somewhat speaks against this being the sole explanation. Interestingly, previous research indicates that lactate may also be produced by non-working muscle or splanchnic organs [34-36]. One may thus speculate that part of lactate production during IHE may have occurred in the liver, for instance as a result of an increased hepatic glycolytic flux during IHE in individuals with type 1 diabetes in whom supraphysiological levels of insulin may have inhibited glucose-6-phosphatase [37].

Could an increased lipid oxidation account for the difference in glucose disposal between IHE and CONT? Indeed, fat oxidation was not significantly different when expressed in absolute values, but fat contribution to total energy production represented $25 \pm 2 \%$ vs $21 \pm 2 \%$ for fat oxidation in IHE and CONT, respectively ( $p=0.03$, data not shown). Of note, levels of NEFA did not significantly differ but tended to be higher during CONT. This paradox may indicate that fat oxidation relied predominantly on intramyocellular lipids (IMCL) and less on peripheral adipose tissue. Contrary to peripheral lipolysis, intramuscular degradation of lipids is not suppressed by insulin [38]. Furthermore, the greater catecholamine response in IHE may have triggered IMCL utilisation due to a stimulatory effect on hormone sensitive lipase [39]. Increased alphaadrenergic vasoconstriction in adipose tissue during intense exercise may have further decreased circulating NEFAs by a capturing effect $[28,40]$. This goes well along with the finding of comparable NEFA levels in the recovery phase.

Previous studies have raised concerns regarding an increased risk of delayed exercise-related hypoglycaemia in IHE due a depletion of glycogen stores [11]. Our findings do not point towards such an effect but we clearly acknowledge that the present study was not powered to assess this specific research question. Glycogen consumption in the present study was comparable in IHE and CONT both in the muscle and the liver. As supported by previous studies [41, 42], muscle glycogen was the most relevant fuel source in both exercise conditions ( $>50 \%$ of total energy yield, data not shown), independently of the prevailing insulin levels.

The strengths of the present study are its standardised and randomised design, comprehensively combining independent techniques to investigate exercise-related fuel metabolism in a setting reflecting a common clinical situation (e.g. exercise without the usually recommended adaptation of insulin doses). We, nevertheless, acknowledge several limitations. First, the complex study design limited the number of participants. Second, analysis of glucose kinetics during exercise was restricted to the last $30 \mathrm{~min}$ of exercise in order to allow sampling during a plateau phase of IEs. Third, oxygen consumption was not continuously measured over the entire cycling session, thereby limiting estimation of energy 
expenditure during and immediately after sprinting. Still, results of continuous heart rate monitoring, which is an accurate estimate for exercise-related energy expenditure, suggest that the investigated exercise protocols were entirely comparable [43]. Fourth, baseline MRS examinations were measured once for IHE and CONT on a separate day since it has been observed during the pilot phase that an MRS directly prior to exercise was too demanding and increased stress hormones. This design might have increased the variations of baseline glycogen values. Finally, we cannot fully exclude the possibility that the ${ }^{13} \mathrm{C}$ enrichment of the oral glucose solution may have led to a small increase of the glycogen signal due to higher enrichment. However, due to the low enrichment used in the present study it can be estimated that a potential effect would be in the order of $1 \%$ or below in liver and muscle, and that an effect would be comparable in IHE and CONT, thereby not affecting direct comparison.

In conclusion, the results of the present study suggest that IHE performed over an extended time period in individuals with type 1 diabetes without prior insulin adaptation translates into lower exogenous glucose requirements compared with iso-energetic CONT exercise. Interestingly, this difference was not related to an increased consumption of hepatic or muscular glycogen in IHE, but was accompanied by a similar hepatic glucose output in both interventions. However, IHE induced a significantly decreased glucose disposal compared with CONT, implying a shift towards consumption of alternative, glucose-competing substrates in IHE. These findings corroborate the flexibility of exercise-related fuel metabolism in type 1 diabetes, indicating a novel and specific metabolic benefit of IHE in addition to its well-known effects on exercise performance. Further studies need to explore the related mechanisms in more depth.

Acknowledgements The authors would like to thank all the volunteers for their participation and enthusiasm. Special thanks go to M. Fiedler and A. Leichtle from the Centre of Laboratory Medicine at the University Hospital Bern for great support in diagnostic aspects, to the study nurses involved in the study, and to E. Grouzmann from the University of Lausanne for support in the analysis of catecholamines.

\section{Compliance with ethical standards}

Funding This study was supported by unrestricted grants from the Swiss National Science Foundation (grant number 320030_149321/1 to CSt) and R\&A Scherbarth Foundation (Switzerland).

Duality of interest The authors declare that there is no duality of interest associated with this manuscript.

Contribution statement The following authors contributed to conception and design of the study: $\mathrm{LB}, \mathrm{CC}, \mathrm{CB}, \mathrm{LT}, \mathrm{MW}$ and CSt; acquisition of data: LB, TZ, TB, AD, NP, CSp, DP, KF, HL, RR, MW, LT, CB and CSt; analysis: LB, TZ, TB, CSp, NP, CC, DP, RR, LT, CB and CSt; and interpretation of data: LB, TZ, LT, MW, CB and CSt. All authors were involved in drafting the article (LB, TZ, LT, CB and CSt), or revising it critically for important intellectual content (LB, TZ, TB, AD, CSp, NP,
CC, DP, KF, HL, RR, MW, LT, CB and CSt). All authors approved the final version to be published. CSt is responsible for the integrity of the work as a whole.

\section{References}

1. Sonnenberg GE, Kemmer FW, Berger M (1990) Exercise in type 1 (insulin-dependent) diabetic patients treated with continuous subcutaneous insulin infusion. Prevention of exercise induced hypoglycaemia. Diabetologia 33:696-703

2. Gibala MJ, Little JP, Macdonald MJ, Hawley JA (2012) Physiological adaptations to low-volume, high-intensity interval training in health and disease. J Physiol 590:1077-1084

3. Weston KS, Wisloff U, Coombes JS (2014) High-intensity interval training in patients with lifestyle-induced cardiometabolic disease: a systematic review and meta-analysis. Br J Sports Med 48:12271234

4. Bussau VA, Ferreira LD, Jones TW, Fournier PA (2006) The 10-s maximal sprint: a novel approach to counter an exercise-mediated fall in glycemia in individuals with type 1 diabetes. Diabetes Care 29:601-606

5. Bussau VA, Ferreira LD, Jones TW, Fournier PA (2007) A 10-s sprint performed prior to moderate-intensity exercise prevents early post-exercise fall in glycaemia in individuals with type 1 diabetes. Diabetologia 50:1815-1818

6. Campbell MD, West DJ, Bain SC et al (2014) Simulated games activity vs continuous running exercise: a novel comparison of the glycemic and metabolic responses in T1DM patients. Scand J Med Sci Sports 25:216-222

7. Dube MC, Lavoie C, Weisnagel SJ (2013) Glucose or intermittent high-intensity exercise in glargine/glulisine users with T1DM. Med Sci Sports Exerc 45:3-7

8. Guelfi KJ, Jones TW, Fournier PA (2005) Intermittent highintensity exercise does not increase the risk of early postexercise hypoglycemia in individuals with type 1 diabetes. Diabetes Care 28:416-418

9. Guelfi KJ, Ratnam N, Smythe GA, Jones TW, Fournier PA (2007) Effect of intermittent high-intensity compared with continuous moderate exercise on glucose production and utilization in individuals with type 1 diabetes. Am J Physiol Endocrinol Metab 292: E865-E870

10. Iscoe KE, Riddell MC (2011) Continuous moderate-intensity exercise with or without intermittent high-intensity work: effects on acute and late glycaemia in athletes with type 1 diabetes mellitus. Diabet Med 28:824-832

11. Maran A, Pavan P, Bonsembiante B et al (2010) Continuous glucose monitoring reveals delayed nocturnal hypoglycemia after intermittent high-intensity exercise in nontrained patients with type 1 diabetes. Diabetes Technol Ther 12:763-768

12. Marliss EB, Vranic M (2002) Intense exercise has unique effects on both insulin release and its roles in glucoregulation: implications for diabetes. Diabetes 51(Suppl 1):S271-S283

13. Fahey AJ, Paramalingam N, Davey RJ, Davis EA, Jones TW, Fournier PA (2012) The effect of a short sprint on postexercise whole-body glucose production and utilization rates in individuals with type 1 diabetes mellitus. J Clin Endocrinol Metab 97:41934200

14. Jenni S, Oetliker C, Allemann S et al (2008) Fuel metabolism during exercise in euglycaemia and hyperglycaemia in patients with type 1 diabetes mellitus - a prospective single-blinded randomised crossover trial. Diabetologia 51:1457-1465 
15. Riddell MC, Milliken J (2011) Preventing exercise-induced hypoglycemia in type 1 diabetes using real-time continuous glucose monitoring and a new carbohydrate intake algorithm: an observational field study. Diabetes Technol Ther 13:819-825

16. Gerrior S, Juan W, Basiotis P (2006) An easy approach to calculating estimated energy requirements. Prev Chronic Dis 3:A129

17. Lefebvre PJ (1985) From plant physiology to human metabolic investigations. Diabetologia 28:255-263

18. Dunand M, Gubian D, Stauffer M, Abid K, Grouzmann E (2013) High-throughput and sensitive quantitation of plasma catecholamines by ultraperformance liquid chromatography-tandem mass spectrometry using a solid phase microwell extraction plate. Anal Chem 85:3539-3544

19. Peronnet F, Massicotte D (1991) Table of nonprotein respiratory quotient: an update. Can J Sport Sci 16:23-29

20. Wolfe RR, Chinkes DL (2005) Isotope tracers in metabolic research: principles and practice of kinetic analysis, 2nd edn. Wiley, Chichester

21. Tounian P, Schneiter P, Henry S, Delarue J, Tappy L (1997) Effects of dexamethasone on hepatic glucose production and fructose metabolism in healthy humans. Am J Physiol 273:E315-E320

22. Steele R, Wall JS, De Bodo RC, Altszuler N (1956) Measurement of size and turnover rate of body glucose pool by the isotope dilution method. Am J Physiol 187:15-24

23. Robert JJ, Koziet J, Chauvet D, Darmaun D, Desjeux JF, Young VR (1987) Use of 13C-labeled glucose for estimating glucose oxidation: some design considerations. J Appl Physiol (1985) 63:1725-1732

24. Schneiter P, Pasche O, Di Vetta V, Jequier E, Tappy L (1994) Noninvasive assessment of in vivo glycogen kinetics in humans: effect of increased physical activity on glycogen breakdown and synthesis. Eur J Appl Physiol Occup Physiol 69:557-563

25. Taylor R, Price TB, Rothman DL, Shulman RG, Shulman GI (1992) Validation of 13C NMR measurement of human skeletal muscle glycogen by direct biochemical assay of needle biopsy samples. Magn Reson Med 27:13-20

26. Gruetter R, Magnusson I, Rothman DL, Avison MJ, Shulman RG, Shulman GI (1994) Validation of 13C NMR measurements of liver glycogen in vivo. Magn Reson Med 31:583-588

27. Moller N, Jorgensen JO, Schmitz O et al (1990) Effects of a growth hormone pulse on total and forearm substrate fluxes in humans. Am J Physiol 258:E86-E91

28. Capaldo B, Napoli R, Di Marino L, Sacca L (1992) Epinephrine directly antagonizes insulin-mediated activation of glucose uptake and inhibition of free fatty acid release in forearm tissues. Metabolism 41:1146-1149

29. Lembo G, Capaldo B, Rendina V et al (1994) Acute noradrenergic activation induces insulin resistance in human skeletal muscle. Am J Physiol 266:E242-E247
30. Miller BF, Fattor JA, Jacobs KA et al (2002) Lactate and glucose interactions during rest and exercise in men: effect of exogenous lactate infusion. J Physiol 544:963-975

31. Lombardi AM, Fabris R, Bassetto F et al (1999) Hyperlactatemia reduces muscle glucose uptake and GLUT-4 mRNA while increasing (E1alpha)PDH gene expression in rat. Am J Physiol 276:E922E929

32. Vettor R, Lombardi AM, Fabris R et al (1997) Lactate infusion in anesthetized rats produces insulin resistance in heart and skeletal muscles. Metabolism 46:684-690

33. Choi CS, Kim YB, Lee FN, Zabolotny JM, Kahn BB, Youn JH (2002) Lactate induces insulin resistance in skeletal muscle by suppressing glycolysis and impairing insulin signaling. Am J Physiol Endocrinol Metab 283:E233-E240

34. Ahlborg G (1985) Mechanism for glycogenolysis in nonexercising human muscle during and after exercise. Am J Physiol 248:E540 E545

35. Bergman BC, Wolfel EE, Butterfield GE et al (1999) Active muscle and whole body lactate kinetics after endurance training in men. J Appl Physiol (1985) 87:1684-1696

36. Wilson TH (1956) The role of lactic acid production in glucose absorption from the intestine. J Biol Chem 222:751-763

37. Renold AE, Hastings AB, Nesbett FB, Ashmore J (1955) Studies on carbohydrate metabolism in rat liver slices. IV. Biochemical sequence of events after insulin administration. J Biol Chem 213: $135-146$

38. Moberg E, Sjoberg S, Hagstrom-Toft E, Bolinder J (2002) No apparent suppression by insulin of in vivo skeletal muscle lipolysis in nonobese women. Am J Physiol Endocrinol Metab 283:E295E301

39. Watt MJ, Stellingwerff T, Heigenhauser GJ, Spriet LL (2003) Effects of plasma adrenaline on hormone-sensitive lipase at rest and during moderate exercise in human skeletal muscle. J Physiol 550:325-332

40. Hodgetts V, Coppack SW, Frayn KN, Hockaday TD (1991) Factors controlling fat mobilization from human subcutaneous adipose tissue during exercise. J Appl Physiol (1985) 71:445-451

41. Chokkalingam K, Tsintzas K, Norton L, Jewell K, Macdonald IA, Mansell PI (2007) Exercise under hyperinsulinaemic conditions increases whole-body glucose disposal without affecting muscle glycogen utilisation in type 1 diabetes. Diabetologia 50:414-421

42. Robitaille M, Dube MC, Weisnagel SJ et al (2007) Substrate source utilization during moderate intensity exercise with glucose ingestion in type 1 diabetic patients. J Appl Physiol (1985) 103:119-124

43. Keytel LR, Goedecke JH, Noakes TD et al (2005) Prediction of energy expenditure from heart rate monitoring during submaximal exercise. J Sports Sci 23:289-297 